\title{
Effect of Social Capital on Mitigating Transaction Uncertainty of Small Enterprises in Sri Lanka
}

\author{
H. M. S. Priyanath ${ }^{1, ~ *, ~ S . ~ P . ~ P r e m a r a t n e ~}{ }^{2}$ \\ ${ }^{1}$ Department of Economics and Statistics, Sabaragamuwa University of Sri Lanka, Belihuloya, Sri Lanka \\ ${ }^{2}$ Department of Economics, University of Colombo, Colombo, Sri Lanka
}

Email address:

priya@ssl.sab.ac.lk (H. M. S. Priyanath)

${ }^{*}$ Corresponding author

\section{To cite this article:}

H. M. S. Priyanath, S. P. Premaratne. Effect of Social Capital on Mitigating Transaction Uncertainty of Small Enterprises in Sri Lanka. Journal of Business and Economic Development. Vol. 3, No. 1, 2018, pp. 1-10. doi: 10.11648/j.jbed.20180301.11

Received: October 5, 2017; Accepted: October 16, 2017; Published: December 14, 2017

\begin{abstract}
Small Enterprises (SEs) do not have capacity to collect and evaluate information to predict future behavior of business environment on one hand and they fail to avoid the hazards from opportunism of exchange partners on the other hand due to the lack of information. SEs develop informal and personal relationships with different members of the network expecting supports in order to overcome their limitation of information. The network relationships lead to build Social Capital (SC) (values of social relationships; i.e. inter-personal trusts, relational norms, flexibility, integrity, common understand etc.) and thereby facilitate access to information which have an influence on mitigating Transaction Uncertainty (TU). Therefore, the study attempted to explore how different dimensions of SC affect the mitigation of TU of SEs in Sri Lanka. The study mainly employed the survey method to gather data using quantitative methodological approach. The data were collected from 373 SEs located in nine districts representing all Provinces in Sri Lanka, conducting face-to-face interviews with the respondents. The data were analysed using Partial Least Squares-Structural Equation Modelling. The results revealed that different dimensions of SC (structural, relational and cognitive) have a significant impact on mitigating TU of SEs in Sri Lanka. Thus, the study has provided sufficient evidences to conclude that SC has a significant impact on mitigating TU of SEs. The study contributes to theoretical knowledge by synthesizing all the dimensions of SC and TU into a new framework and testing it empirically which extends the transaction cost economics in the context of SEs in Sri Lanka. The study contributes to the methodology quantifying SC of SEs using a multi-dimensional conceptual model. The study provides important insights for policy makers to focus their strategies to new direction rather than conventional supporting approaches to develop SEs.
\end{abstract}

Keywords: Small Enterprises, Social Capital, Transaction Uncertainty

\section{Introduction}

Small Enterprises (SEs) have higher Transaction Uncertainty (TU) due to asymmetrical information [1]. Due to asymmetrical information, SEs do not have capacity to collect and evaluate information to predict future behavior of business environment on one hand and they fail to avoid the hazards from opportunism of exchange partners on the other hand [2], [3]. Problem of information asymmetric arises in SEs due to various barriers including lack of knowledge to access and assess information, lack of time and capacity to gather and handle information, lack of resources to access and evaluate information, lack of knowledge and experience to avoid opportunism of exchange partners [2], [4].
Therefore, the Transaction Cost (TC) is very high and as a result, the failure rate of SEs is also very high [2], [4], [5], [6].

SEs use their informal and personal connections in order to get required information and resources [7], [8]. These informal and personal connections are based on network relationships with family members, relatives, friends, supportive institutions and the others [7], [9], [10]. Such network relationships generate different values such as interpersonal trust, relational norms, and common understand etc. which are called as Social Capital (SC) [7], [9], [11]. One of the key benefits of SC is that it facilitates to access information and increases information's quality and relevance [12], [13], [14]. Thus, the SC permits to access information 
reducing information asymmetric [15], [16] and helps SEs to mitigate information asymmetric enabling to access information which allows to mitigate TU [17], [18].

In literature, a few researchers analysed the relationship between SC and TU. Lohtia and Krapfel (1994) [19] found that strong buyer-seller relationship affects the transaction specific assets reducing TU. Paswan and Young (1999) [20] revealed that when solidarity exists partners tend to support each other such as by providing business advice which lead to decrease TU. Misztal (1996) [21] explained that exchange partners fulfil all of his responsibilities and obligations correctly and are honest, fair and perform their role properly and adequately, it affect the decrease of TU. However, a complete academic work particularly SEs pertaining to examine how different dimensions of SC affect the mitigation of TU represents a significant gap. Therefore, main objective of this paper is to bridge this gap, exploring how different dimensions of SC affect the mitigation of TU, particularly SEs in Sri Lanka.

\section{Literature and Hypotheses}

Uncertainty is defined as a lack of knowledge about the state in the future [22]. Williamson (1991) [23] defined that TU as the circumstances surrounding an exchange which cannot be specified ex-ante (i.e. environmental uncertainty) and the performance which cannot be easily verified ex-poste (i.e. behavioral uncertainty). Environmental uncertainty refers to unexpected changes in economic environments surrounding the transaction [24]. It is defined as the inability to predict changes in relevant factors surrounding future transaction [25]. The TC theory mainly considers the uncertainty that exists in an economic environment which is defined as the uncertainty from demand and supply [26]. Demand uncertainty simply refers to the inability of the prediction of future state of prices, quantity and the market size [27]. On the supply side, uncertainty can arise from the internal operations of the firm as well as from the external developments in technology. Supply uncertainty simply refers to the inability of the prediction of future state of input prices, supply and volume, technological changes etc. [24], [28], [29], [30]. Behavioral uncertainty is that which may be present in a transaction due to the opportunistic preferences of the transacting parties [29]. Inability to predict future behavior of exchange partners is referred as behavior uncertainty [31], [32].

TU arise due to asymmetrical information occurred in imperfect market. It refers to the situation where all parties to a transaction face incomplete levels of information [33]. SEs use their informal and personal connections in order to get required information [34]. These informal and personal connections do not have formal and written agreement but these connections are based on network relationships with family members, relatives, friends, supportive institutions and the others [34], [35]. Literature describes that the network relationship i.e. network size and density, strength of ties, relational qualities (inter-personal trust, relational norms) and common understand among members lead to generate SC [7], [9], [11]. SC facilitates to access information. Heide and John (1992) [36] empirically observed that information exchange between exchange partners reduced information asymmetry. Nahapiet and Ghoshal (1998) [11] presented that inter-personal trust among network members encourages cooperation, and it opens up people for accessing information. Network members who trust each other are more willing to share information since they have no fear of being exploited by the other members. Hence, inter-personal trust that leads to share information generates strong cooperation among them. Kale, Singh and Perlmutter (2000) [37] indicated that SC based on mutual trust creates a basis for learning and knowledge transfer across the exchange interface and reduces opportunistic behavior. Trust facilitates conflict resolution by encouraging cooperative orientation between parties to adapt to the changing environmental situations [3]. Thus, many scholars explained that different dimensions of SC facilitate to share information that leads to mitigate TU.

$\mathrm{SC}$ is the value and resources that generated from interpersonal relationships. Coleman (1988) [38] claimed that unlike other types of capital, SC is the structure of relations between actors and among actors. According to Putnam (1995) [39], key features of SC are; a) moral obligations and norms, b) social values (especially trust) and c) social networks (especially voluntary associations) all facilitates coordination and cooperation for the mutual benefit. SC consists of features of relationship among individuals such as networks, high levels of interpersonal trust and norms of mutual supports which act as resources for individuals and facilitate for collective action [11], [12].

SC has three dimensions; structural, relational and cognitive [11]. Resources that generate due the pattern of relationships among individuals are called as Structural Social Capital (SSC). The SSC discusses the pattern of connections among the members of the network. Important aspects of the SSC are the pattern of ties between the members of a social network; network structure based on density of ties and frequency of connectivity and interaction [11]. Thus, scholars highlighted that network size (total number of actors that the focal firm is connected to) and the density of network (existing connections out of potential ties) are as the two reflective dimensions of SSC [34], [40]. The Relational Social Capital (RSC) refers as resources that generate from the value of relationships among individuals. The value of relationship is reflected by the strength of relationships and qualities of the relationships [34], [40]. The RSC has two broad dimensions: a) strength of relationships and b) qualities of relationships which are reflected by interpersonal trust (the willingness to be vulnerable to another person), norms (generalized expectations of behavior, such as norms of reciprocity, flexibility, solidarity, reciprocity and role of integrity) [32], [41], [42]. Cognitive Social Capital (CSC) is the resources that provide shared vision or common understand among network members [11]. In business perspective, CSC implies the value of common 
understanding among exchange partners [43]. This aspect of social capital consists of the value such as common vision that support a common understanding of shared goals, norms of action and social trust in a social setting [44]. The way that the network members show their norms, trust and commitment in reality is the CSC [8], [45].

\subsection{Structural Social Capital and Transaction Uncertainty}

Network structure is channel for information [46]. Networks play a vital role in facilitating processes of knowledge sharing and learning among firms. Especially for SEs, network structure is essential for the exchange of information and knowledge. SEs that is central in a network likely have a greater potential to gain and exchange information with other actors because of its locational advantages in the network [44]. Information gain from network helps SEs to predict more accurately the market share, purchase and sales volume and prices which are the attributors of environmental uncertainty [1]. Network relationships have ability to reduce TC associated with behavioural uncertainty (potential risk of opportunism) communicating and passing information about dishonest and cheated partners [7]. Information and assistance gained from members of network function as a mechanism for reducing threats of uncertainty. For example; according to $\mathrm{Lu}$ (2007) [7], SEs can consult members of the network to know in advance whether the potential business partners are honest before making contract. Network relationships help SEs to select better exchange partners assessing his previous performances through the members of network and thereby SEs are able to minimize the potential behavioral uncertainty [47], [48]. Thus, network structure helps SEs to minimize both environmental and behavioral uncertainties. Therefore, the study predicts that;

H1 Structural social capital of a SE relates negatively to the transaction uncertainty of the $S E$.

\subsection{Relational Social Capital and Transaction Uncertainty}

TU arises due to information asymmetries, imperfect communication and verification difficulties, all contribute increase the TC [3]. From a TC perspective, the most exciting argument for the efficiency of inter-personal relationships that involved trust is simply that trust reduces the feeling to guard against opportunistic behavior of the exchange partner [49]. Under conditions of low trust, lengthy and difficult negotiations over unforeseen contingencies are likely to take place between exchange partners because of the possibility of ex-post opportunism [33]. In addition, contractual safeguards are put in place to protect transaction, which arise TC [33]. In contrast, under high trust conditions, SEs are less motivated to rely on elaborate safeguards for specifying, monitoring, and enforcing agreements. High in trust relations, therefore, imply more efficient exchange governance [3]. Thus, inter-personal trust between SEs and exchange partners facilitate to mitigate behavioral uncertainty.
In uncertain environments, the ability to draw on wellestablished honest relationships is an important asset. With relational norms, the self-interest of the exchange partners encourages both partners to adjust and accommodates each other's priorities and behave reasonably in uncertain times [50]. Unlike contract re-negotiations and re-specifications that can sometimes follow a period of uncertainty, adaptations to the relational approach of governance are not as costly, or time consuming [50]. Heide and John (1992) [36] explained that norm of flexibility as the practice of making necessary modifications in favor of the disadvantaged party if changed circumstances prove damaging to one party. When strong relationship develops between exchange partners, the norm of flexibility emerges in the day today dealings between the agents [52]. If both want the partnership to continue, they have to be flexible and if not the relationship would come to an end. Moreover, due to uncertainty it is impossible to determine all the conditions of the exchange in advance. For partners that have entered into a verbal (informal) or written (formal) agreement, if flexibility is there, they will make modifications/adjustments to the original contract when circumstances change [36]. Flexibility helps make adjustments to suit the reasonable needs of the exchange party.

Flexibility refers as the elastic behavior of exchange partners including two components: flexibility towards behavioral uncertainty and flexibility towards environmental uncertainty [36], [52]. In the context of SEs, flexibility refers to making allowances for one party if they are unable to fulfil an obligation. Under flexibility, there is no much need to cover for every possible circumstance in advance since exchange partners adapt to changing circumstances as they occur. Dwyer and Gassenheimer (1992) [53] revealed that flexibility leads channel partners to make more attempts at satisfying each other. This essentially implies that they would behave without opportunism so as to satisfy the trading partner. Heide and John (1992) [36] stated that if flexibility is there, exchange partners will make modifications to the original contract when circumstances change. Since changes are faced as they occur, there is no need to write a complete contract in advance. Thus, uncertainty becomes decrease when flexibility exists. When parties are flexible, they would face unexpected circumstances as they occur and do not attempt to draw a complete contract before the transaction. Thus, RSC facilitates SEs to mitigate both environmental and behavioral uncertainty. Therefore, the study proposes that;

H2 Relational social capital of a SE negatively relates to the transaction uncertainty of the $S E$.

\subsection{Cognitive Social Capital and Transaction Uncertainty}

Common understanding is viewed as SEs having similar values and expectations of behavior. Common understanding about the ways of interaction leads to more and better opportunities for sharing information without any confusion. As a result, network members who share a common vision will be more likely to share information [44]. Hence, the common understanding amongst the network members, leads 
to sharing of information, which facilitates SEs to predict possible environmental uncertainties. This enables SEs to govern uncertainty negotiating with their exchange partners. On the other hand, when network members have the same perceptions about their mutual performances, they supported each other exchanging their ideas and helping them to avoid uncertainties [44]. With collective goals, network members are motivated to trust another, as they can expect that they all work for collective goals and will not behave opportunistically (Miller et al., 2007). Thus, collective goals provide the harmony of interests that help to avoid possibility of opportunistic behavior [44]. Common (1988) [38] understanding encourages exchange partners to share information with focal SEs and enable SEs to govern transaction uncertainty. Both parties have strong CSC; they will support each other without having opportunistic behavior, which erases behavioral uncertainty. Therefore, the researcher proposes that;

H3 Cognitive social capital of a SE negatively relates to the transaction uncertainty of the SE.

\section{Methodology}

Quantitative approach is employed to study the research problem and the survey method was selected to gather data. Only owner manager manufacturing SEs, which are classified according to 2 digit levels of ISIC-Revision-4 were selected to gather data. Department of Census and Statistics (DCS) of Sri Lanka defines SEs as 'establishment with 5 - 24 persons engaged' and the same definition was used to select SEs for the survey. According to the DCS, there were 71,126 SEs dispersed in Sri Lanka and the study employed those SEs as the study population.

Multi-stage sampling method was adopted to determine the sample. First, the study selected only the SEs classified under manufacturing category as the sample frame. According to the Economic Census in 2013/2014, there were 14,185 SEs belonging to the category of manufacturing establishments since they frequently engage in transaction activities by purchasing inputs from the suppliers and selling outputs for buyers. Second, using the sample frame $(14,185$ of SEs), 373 of units were decided using the sample size determination formula developed by Krejcie and Morgan (1970) with 95 percent confidence level and 5 percent margin of error. Third, the sample is distributed according to the percentage share of the SEs located in each district and determine the number of firms to represent all the district in Sri Lanka. Then, SEs of each districts were listed out according to ISIC category and the sample were selected using stratified sampling method to represent all the manufacturing industrial divisions.

The study used two step procedure to develop questionnaire. Initially, a pool of items of each dimensions reviewing empirical literature has been generated and carefully selected items, which are more relevant to measure the particular dimension of the constructs. Thus, the questionnaire items were designed systematically based on literature published in cited journals. Each items were measured at an ordinal level with 7-point Likert scales (1 Strongly disagree; 2 - Disagree; 3 - Somewhat disagree; 4 Neither agree nor disagree; 5 - Somewhat agree; 6 - Agree; 7 - Strongly agree). Each respondent was asked to state their agreement to the statements using these rankings. Then, a pilot survey was conducted prior to the main questionnaire survey in order to verify whether the questions are understood; whether instructions are clear; whether the order of the questions is appropriate and the questions are uninspiring etc. This helped to increase the validity and the reliability of the study. Data were collected for the questionnaire conducting face to face interviews. The unit of analysis is each owner of SEs because the owner is the 'entrepreneur' in many SEs who starts and manages the business.

Partial Least Squares-Structural Equation Modelling (PLSSEM) was used to test the hypothetical relationships because it helps to examine the interrelationship between multiple independent and dependent variables and facilitates the evaluation of relationships between more than one construct simultaneously. Measurement model was evaluated employing reliability and validity tests and the efficiency of the structural model was evaluated by multi-collinearity issues, $R^{2}$, effect size $\left(f^{2}\right)$ and predictive relevance $\left(Q^{2}\right)$. The smart PLS (version 2) software was used to analyse data.

SSC: The study assessed SSC using network size and network density. The network size of the SEs was simply measured as the number of persons that SEs is directly connected to. This measurement was adopted by Bhagavatula (2009) [9]; Priyanath (2017c) [34]. The network density of the SEs was assessed as the total number of persons that the SE deals business activities with exchange partners. The network density was measured as the percentage of close relationships within the total number of possible relationships. This was adopted by Bhagavatula (2009) [9]; Priyanath (2017c) [34].

RSC: The study considered the RSC as assets embedded with strength and quality of relationships. It referred to the kinds of relationships that the actor has developed with each other through a history of interactions [39], [54]. Considering the SEs, the RSC refers to the strength of relationships that SEs have developed with each other and quality of relationship including inter-personal trust and relational norms embedded with the relationships.

The strength of relationship was measured using Network Strength Index. It refers to what extent SEs maintains close ties with regular interaction in a long period. The study used an index to measure the network strength. Lu et al. (2012) [55] adopted the same index. The study asked respondents to select the most important 12 members of different categories of network and provide answers to the following questions. How well do you know the person (very well, somehow, or very little)? How often do you contact this person (daily, weekly, or monthly)? How many years do you know this person? For the first two questions, a weight of 1, for answers of "very well" and "daily", 0.5 , for "somehow" and 
"weekly", and 0.1, for "very little" and "monthly" are assigned. The network strength index was created by multiplying the three answers. The higher this value is, the stronger the ties are.

Ganesan (1994) [56] represented trust as a twodimensional construct of credibility and benevolence (behavioral dimension). Inter-personal trust refers to the belief of entrepreneur that the network member is creditable (honest, flexible, fair and in no circumstance will purposely do anything to damage the relationship) and always shows the creditability by action (benevolence). Accordingly, creditability was evaluated employing three components i.e. reliability, predictability, and fairness and three items were used to measure benevolence all of which have been adopted by [3], [55], [56],

Study defined relational norms as the expectations about the behavior that are at least partially shared informal agreements between parties that have been shown to govern their relationships. Relational norms between SEs and network members were measured using five variables; information exchange, flexibility, solidarity, role of integrity and reciprocity. These variables have been adopted by Doucette (1996) [57]; Dyer and Chu (2003) [41]; Heide and John (1992) [36]; Rokken et al. (2003) [42].

CSC: The CSC refers to the resources that provide a shared representation, an interpretation and systems of meaning. This dimension attributed common understanding, common perspectives and shared congruence, or generally agreed upon meanings [11]. CSC is embodied in attribute like a shared code or a shared paradigm that facilitates a common understanding of collective goals. A shared goal embodies the collective goals and aspirations among the network members [58].

Transaction Uncertainty: The environmental uncertainty was measured using demand and supply uncertainty. The demand uncertainty was measured employing two items: extent of predictability of market share and prices which were employed for empirical studies by scholars Artz and Brush (2000) [28]; Bstieler (2005) [59]; Noordeweir et al. (1990) [24]. Meanwhile, the supply uncertainty was measured as the extent of unpredictability of supply volume and input prices adopted by Artz and Brush (2000) [28], Bstieler (2005) [59], Chen and Chen (2003) [31]. On the other hand, behavioral uncertainty of SEs has been operationalized by the degree of the difficulty associated with assessing the performance of exchange partners [47], [48]. Three items (developed by Chen and Chen, 2003 [43]): the degree of difficulty in assessing the performance of exchange partners, the risk of opportunistic behavior of exchange partners and extent of accessibility whether the exchange partners breach pre-agreements to maximize their own benefit, were employed in order to measure behavioral uncertainty of SEs.

\section{Results and Discussion}

With regard to the personal characteristics of the sample, the majority (90.2 percent) of the OSEs were males while female owners contribute 9.8 percent to the sample. Mean age of the owners is 51 years. The owners' age varies from minimum age of 27 to the maximum age of 71 . The majority of the owners (80.6 percent) belong to the age category between 40 years to 59 years, while only 5.4 percent fall into the under 39 years group, and 13.3 percent belong to the over 60 year group. In view of the academic background of the OSEs, they have a good formal educational background. Mean education of the owners is 3.6, which implies the average education of the owners varies between $\mathrm{O} / \mathrm{L}$ and A/L. Less than 40 percent of the owners have obtained below G.C.E. Ordinary Level qualification while 6.5 percent of the owners have a degree. Nearly 60 per cent ( 53.3 percent: up to $\mathrm{A} / \mathrm{L}+6.5$ percent: Degree or above $=59.8$ percent) have academic qualifications beyond the G.C.E. Advance Level. In addition to formal education, business experience is more important in particular for the OSEs. Mean business experience of the owners is 15 years. 27 percent of the owners have less than 10 year experience in the business field while 7.9 percent of the owners have more than 30 year experiences. 43.4 percent have business experience between 10 year and 19 year while 21.6 percent have business experience between 20 year and 29 .

\subsection{Reliability and Validity of Constructs}

Based on PLS-SEM measurement of outer model, first, the study evaluated 12 of first order latent variables. The table 1 shows standardized factor loadings which were above than the minimum threshold criterion 0.7 confirming the indicator reliability of first order reflective constructs. In addition, the table 1 further shows that all the factor loadings were statistically significant at 0.05 significance level. The Cronbach's $\alpha$ was higher than the required value of 0.7 and composite reliability was higher than the recommended 0.7 value. Higher value of the Cronbach's $\alpha$ and the composite reliability confirm the convergent validity of the first order constructs. Regarding the discriminant validity, none of the inter-construct correlation value was above the square-root of the AVE and satisfied the criterion of the discriminant validity of first order constructs.

The second-order constructs were developed using latent variable scores of the first-order constructs. Indicator reliability of four latent variables at the second order level in the hierarchical model were evaluated. All path coefficients (standardised factor loadings) were well above the threshold value 0.7 (see table 2). The bootstrapping procedure was conducted to estimate the significance of each path coefficient by examining the t-statistics. All the t-statistics were significant at 0.05 significance level (see table 2). Hence, the results show the strong evidence for indicator reliability of the second order constructs. Table 2 displays that the Cronbach's $\alpha$ was higher than the required value of 0.7 and composite reliability was higher than the recommended 0.7 value. With a higher level of the Cronbach's $\alpha$ and composite reliability, the second order constructs were developed in reliable manner. AVE for the 
each construct was higher than the required value 0.5 . The results confirm the convergent validity of the second order construct (see table 2). Discriminate validity of the second order constructs showed that none of the inter-construct correlation value was above the square-root of the AVE and satisfied the criterion of the discriminant validity of the second order constructs.

Table 1. Analysis of the First Order Constructs.

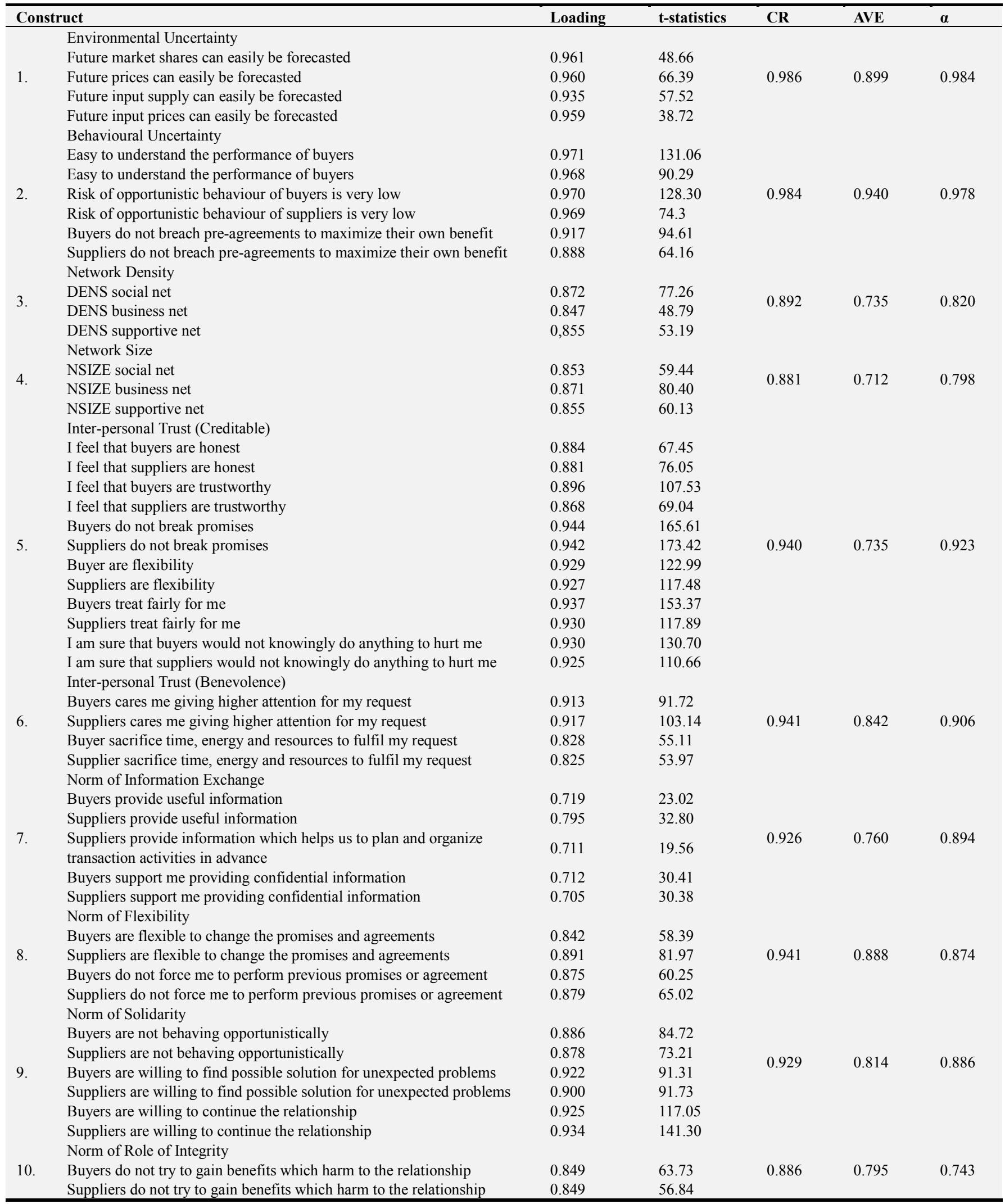




\begin{tabular}{|c|c|c|c|c|c|c|}
\hline \multicolumn{2}{|c|}{ Construct } & \multirow{2}{*}{$\begin{array}{l}\text { Loading } \\
0.857\end{array}$} & \multirow{2}{*}{$\begin{array}{l}\text { t-statistics } \\
66.28\end{array}$} & \multirow{2}{*}{$\mathbf{C R}$} & \multirow{2}{*}{ AVE } & \multirow[t]{2}{*}{$\alpha$} \\
\hline & Buyers do not engage in cheating & & & & & \\
\hline & Suppliers do not engage in cheating & 0.894 & 82.58 & & & \\
\hline & Norm of Reciprocity & & & & & \\
\hline \multirow{3}{*}{11.} & Buyers ignore unexpected mistakes & 0.892 & 87.92 & \multirow{3}{*}{0.858} & \multirow{3}{*}{0.751} & \multirow{3}{*}{0.669} \\
\hline & Suppliers ignore unexpected mistakes & 0.880 & 73.31 & & & \\
\hline & Shared Vision & & & & & \\
\hline & Share common ambitions & 0.865 & 64.18 & \multirow{3}{*}{0.869} & \multirow{3}{*}{0.769} & \multirow{3}{*}{0.702} \\
\hline & Avoid distress & 0.865 & 63.68 & & & \\
\hline & Share new business opportunities & 0.861 & 48.56 & & & \\
\hline
\end{tabular}

$(n=373)$.

Source: Survey data, 2016.

Table 2. Analysis of the Second Order Constructs.

\begin{tabular}{|c|c|c|c|c|c|c|}
\hline & Construct & Loading & t-statistics & CR & AVE & $\boldsymbol{\alpha}$ \\
\hline \multicolumn{4}{|c|}{ Transaction Uncertainty } & 0.946 & 0.898 & 0.887 \\
\hline \multirow[t]{2}{*}{1.} & $\begin{array}{l}\text { Environmental } \\
\text { Uncertainty }\end{array}$ & 0.940 & 142.50 & & & \\
\hline & $\begin{array}{l}\text { Behavioural } \\
\text { Uncertainty }\end{array}$ & 0.955 & 182.35 & & & \\
\hline \multirow{6}{*}{2.} & Norms & & & & & \\
\hline & Flexibility & 0.933 & 125.91 & & & \\
\hline & $\begin{array}{l}\text { Information } \\
\text { Exchange }\end{array}$ & 0.882 & 78.56 & 0.949 & 0.799 & 0.933 \\
\hline & Reciprocity & 0.815 & 33.50 & & & \\
\hline & Role of Integrity & 0.877 & 55.79 & & & \\
\hline & Solidarity & 0.936 & 148.11 & & & \\
\hline \multirow{3}{*}{3.} & Inter-personal Trust & & & & & \\
\hline & Benevolence Trust & 0.970 & 270.63 & 0.969 & 0.942 & 0.937 \\
\hline & Creditable trust & 0.969 & 256.31 & & & \\
\hline
\end{tabular}

$(n=373)$.

Source: Survey data, 2016.

\subsection{Results of the Structural Model}

The efficiency of the structural model were assessed using five step approach suggested by Hair et al. (2013). First, Multi-collinearity issues were assessed. The study calculates VIF and tolerance level with the support of linear regression option in SPSS (version 21.0).

Considering the collinearity between independent constructs and dependent constructs in the structural model, results indicated that there are no multi-collinearity issues among variables. VIF values for all the path show minimal collinearity, ranging from 1.220 to 3.121 . These values are significantly less than the recommended threshold value of 5.00. The tolerance levels range from 0.334 to 0.820 exceeding 0.20 . These results provide a strong evidence for the absent of multi-collinearity issues between the independent constructs and the dependent constructs in the structural model. Second, the study assessed the significance of the path coefficients using $\beta$ value and t-statistics. In view of both path coefficients and t-statistics, Table 3 shows that all the hypothetical relationships were significant. Third, the explanatory power of dependent variable was substantial $\left(\mathrm{R}^{2}=0.636\right)$. Fourth, predictive relevance $\left(\mathrm{Q}^{2}\right)$ of rational ability is 0.628 which displays a substantial higher explanatory power.
Table 3. Path Coefficients and Significance.

\begin{tabular}{lllll}
\hline & Relationship & $\boldsymbol{\beta}$ & T & Result \\
\hline$H 1$ & SSC -> TU & $-0.231 * * *$ & 4.98 & Supported \\
$H 2$ & RSC -> TU & $-0.377 * * *$ & 7.43 & Supported \\
$H 3$ & CSC -> TU & $-0.268 * * *$ & 4.10 & Supported \\
\hline
\end{tabular}

$* * * \mathrm{p}<0.01 .(\mathrm{n}=373)$.

Source: Survey data, 2016.

With regard to the influence of SSC on TU, the Table 3 shows that SSC of SEs has a significant impact on the mitigation of TU by 23 percent $(\beta=-0.231)$, the regression coefficient is positive significant (t-value $=4.98)$. Thus, hypothesis $\mathrm{H} 1$ is strongly proved by empirical data. The results confirmed that the SSC of the SEs has an influence to mitigate TU. Lohtia and Krapfel (1994) [19] provide similar finding that strong network relationship reduces TU. The Table 3 further shows that the RSC significantly affects the decrease of TU by 37.7 percent $(\beta=-0.377$ and $\mathrm{t}$-value $=$ 7.43). Thus, the hypothesis $\mathrm{H} 2$ is strongly proved by the survey data. Many scholars (Bromiley and Cummings, 1995 [49]; Carey, 2011 [50]; Heide and John, 1992 [36]; Ivens and Blois, 2004 [52]; Zaheer et al., 1998 [3]) have provided similar findings highlighting that the strength of relationships among parties affects the decrease of the TU. Lohtia and Krapfel (1994) [19] found that the strong buyer seller relationship affects the decrease of TU. Zaheer et al. (1998) [3] explained that the strong relationships among the members mitigate the information asymmetries by allowing more open and honest sharing of information and thereby mitigate TU. Bromiley and Cummings (1995) [49] found that the trust reduces both environmental and behavioral uncertainty. Zaheer et al. (1998) [3] found that high trust reduces uncertainty. According to Boyle, Dwyer, Robicheaux and Simpson (1992) [60], flexibility prevents the use of threats by the exchange partners. As observed by Heide and John (1992) [36], under flexibility, exchange parties make necessary modifications in favor of the disadvantaged party if changed circumstances prove damaging to one party. This implies that the partners are not opportunistic. Thus, many scholars empirically support revealing that there is a positive relationship between relational qualities and uncertainty. The results of the current study also conform that RSC of SEs have a negative impact on transaction uncertainty of SEs in Sri Lanka. Considering the influence of the CSC on TU, the 
results show that it significantly affects the decrease of TU ( $\beta$ $=-0.268$ and $\mathrm{t}$-value $=4.10)$. Thus, the hypothesis $\mathrm{H} 3$ his strongly proved by the results. Tsai and Ghoshal (1998) [44] explained that the members of network have the same perceptions about their mutual performances, they supported to each other exchanging their ideas and helping them to avoid TU.

\section{Conclusion}

The study analysed the effect of SC on mitigating TU of SEs in Sri Lanka. To achieve this aim, working hypotheses have been developed to test how each dimension of SC affects the TU of SE in Sri Lanka by synthesising the SC theory with the TC theory. The results reveal that all the dimension of SC have significant negative impact on the mitigating TU. The study has made several contributions to the knowledge. First, the study synthesised all the dimensions of SC and TU into a new framework. It explains how the different dimensions of SC affect the mitigation of TU and thus extends the knowledge about the relative efficacy of theories into a different economic and social context. Second, this study makes important contributions to the literature by providing empirical evidences related to SC and TU of SEs in Sri Lanka. Third, the critical issue faced by SE sector is that the sector has higher mortality rate due to the limitations mostly reflected by TC. The study extends the application of the SC theory with the TC theory to understand an alternative solution for this critical issue. The empirical results provide sufficient evidences to understand the strength of SC to govern TU rather than the market mechanism, conforming the complementary effect of SC in governing TU. The study recommends that mechanism should be developed to generate strong SC between SEs and new exchange partners (organizing network formation activities such as seminars, trade fairs etc., providing information about reliable or guaranteed exchange partners through a webpage of responsible agency) in order to mitigate TU of SEs.

\section{References}

[1] Ahmad, N. H. and Seet, P. S. (2009). Dissecting behaviors associated with business failure: A qualitative study of SME owners in Malaysia and Australia. Asian Social Science, 5(9), 98-104.

[2] Nooteboom, B. (1993). Firm size effect on transaction cost, Small Business Economics, 5, 283-295.

[3] Zaheer, A., McEvily, B. and Perrone, V. (1998). Does trust matter? Exploring the effects of Inter-organizational and interpersonal trust on performance. Organization Science, 9(2), 141-159.

[4] Carmel, E., and Nicholson, B. (2005). Small firms and offshore software outsourcing: high transaction costs and their mitigation. Journal of Global Information Management, 13(3), 33-54.

[5] Agwu, M. O. and Emeti, C. I. (2014). Issues, Challenges and
Prospects of Small and Medium Scale Enterprises (SMEs) in Port-Harcourt City in Nigeria. European Journal of Sustainable Development, 3(1), 101-114.

[6] Fatoki, O. (2011). The impact of human, social and financial capital on the performance of small and medium-sized enterprises (SMEs) in South Africa. Journal of Social Science, 29(3), 193-204.

[7] Lu, H. (2007). The role of guanxi in buyer-seller relationships in China, $\mathrm{PhD}$ thesis, Wageningen University, China.

[8] Priyanath, H. H. S. and Premaratne, S. P. (2015). Effect of social capital on transaction cost: a case study of small enterprises in Sri Lanka, International Journal of Arts and Commerce, 4(4), 127 - 140.

[9] Bhagavatula, S. (2009). Weaving social networks performance of small rural firms in India as an outcome of entrepreneurs' social and human capital. PhD Dissertation, Visakhapatnam University, India.

[10] Priyanath, H. H. S. and Premaratne, S. P. (2017). Power of social capital on mitigating transaction cost of small enterprises in Sri Lanka: An Empirical Investigation, International Journal of Arts and Commerce, 6(4), 17 - 35.

[11] Nahapiet, J. and Ghoshal, S. (1998). Social capital, intellectual capital, and the organizational advantage. Academy of Management Review, 23(2), 242-266.

[12] Adler, P. S. and Kwon, S. W. (2002). Social capital: prospects for a new concept. The Academy of Management Review, 27(1), 17-40.

[13] Burt, R. (1992). Structural Holes: The Social Structure of Competition, Harvard University Press: Cambridge, Massachusetts.

[14] Granovetter, M. (1983). The strength of weak ties: a network theory revisited. Sociological Theory, 1(2), 201-233.

[15] Bwalya, R., Mugisha, J., and Hyuha, T. (2013). Transaction costs and smallholder household access to maize markets in Zambia. Journal of Development and Agricultural Economics, 8(9), 328-336.

[16] Priyanto, E., Mazkie, M., and Khusaini, M. (2014). Effects of asymmetric information, transaction cost to corporate governance, and public organization performance. IOSR Journal of Business and Management, 15(6), 14-27.

[17] Henningsen, G. A. and Henning, C. H. C. A. (2013). Networks and transaction costs. American Journal of Agricultural Economics, 94(2), 377-385.

[18] Richman, B. D. (2006). How community institutions create economic advantage: Jewish Diamond merchants in New York. Law and Social Inquiry, 31(2), 383-420.

[19] Lohtia, R. and Krapfel, R. E. (1994). The impact of transaction specific investment on buyer - seller relationship. Journal of Business and Industrial Marketing. 9(1), 6-16.

[20] Paswan, A. K. and Young, A. (1999). An exploratory examination of the relationship between channel support mechanisms and relational norms in an international context. Journal of Business \& Industrial Marketing, 14(5), 445-455.

[21] Misztal, B. (1996) Trust in Modern Societies. Cambridge: Polity Press. 
[22] Arrow, K. J. (1974). The Limits of Organization. Norton and Company, New York, NY.

[23] Williamson, O. E. (1991). Comparative economic organization: the analysis of discrete structural alternatives. Administrative Science Quarterly, 36, 269 - 296.

[24] Noordewier, T. G., John, G and Nevin, J. R. (1990). Performance outcomes of purchasing arrangements in industrial buyer vendor relationships. Journal of Marketing, 54(4), 80-93.

[25] Carey, S. and Lawson, B. (2011). Governance and social capital formation in buyer-supplier relationships. Journal of Manufacturing Technology Management, 22(2), 152-170.

[26] Li, S., and Lin, B. (2006). Accessing information sharing and information quality in supply chain management. Decision Support Systems, 42(3), 1641-1656.

[27] Wernerfelt, B., and Karnani, A. (1987). Competitive strategy under uncertainty. Strategic Management Journal, 8(2), 187194.

[28] Artz, K. W. and Brush, T. H. (2000). Asset specificity, uncertainty and relational norms: an examination of coordination costs in collaborative strategic alliances, Journal of Economic Behavior and Organization, 42(4), 337-362.

[29] John, G. and Weitz, B. A. (1988). Forward integration into distribution: an empirical test of transaction cost analysis. Journal of Law, Economics, \& Organization, 4(2), 337-355.

[30] Yenidogan, T. G. (2013). The impact of transaction attributes and trust on ex-post opportunism. International Journal of Management Sciences and Business Research, 2(6), 39-44.

[31] Chen, H. and Chen, T. J. (2003). Governance structures in strategic alliances: transaction cost versus resource based perspective. Journal of World Business, 38(5), 1-14.

[32] Wu, W. P. and Choi, W. L. (2005). Transaction cost, social capital and firms' synergy creation in Chinese business networks: an integrative approach. Asia Pacific Journal of Management, 21(3), 325-343.

[33] Williamson, O. E. (1981). The economics of organization: transaction costs approach. American Journal of Social, 87(3), 548-577.

[34] Priyanath, H. M. S. (2017). Effect of network structure on transaction costs of small enterprises in Sri Lanka: An empirical study. Journal of Small Business and Entrepreneurship Development, 5(1), 19-34.

[35] Priyanath, H. M. S. and Premaratne, S. P. (2017). Impact of Information Accessed through Social Capital on Rational Ability of Owner Manager Small Enterprises in Sri Lanka. European Business \& Management. 3(4): 65-75.

[36] Heide, J. B. and John, G. (1992). Do norms matter in marketing relationships? The Journal of Marketing, 56(2), 3244.

[37] Kale, P., Singh, H. and Perlmutter, H. (2000). Learning and protection of proprietary assets in strategic alliances: building relational capital. Strategic Management Journal, 21(3), 217237.

[38] Coleman. J. S. (1990). Foundations of Social Theory, London: Harvard University Press.
[39] Putnam, R. D. (1995). Making democracy work: civic traditions in modern Italy. Princeton: Princeton University Press.

[40] Babaei, H., Ahmad, N. and Gill, S. S. (2012). Bonding, bridging and linking social capital and empowerment among squatter settlements in Teheran, Iran. World Applied Sciences Journal, 17(1), 119-126.

[41] Dyer, J. H. and Chu, W. J. (2003). The role of trustworthiness in reducing transaction costs and improving performance: empirical evidence from the United States, Japan, and Korea. Organization Science, 14(1), 57-68.

[42] Rokkan, A. I., Heide, J. B. and Wathne, K. H. (2003). Specific investments in marketing relationships: expropriation and bonding effects. Journal of Marketing, 40(2), 210-224.

[43] Chen, H. and Chen, T. J. (2008). Governance structures in strategic alliances: transaction cost versus resource based perspective. Journal of World Business, 38(5), 1-14.

[44] Tsai, W. and Ghoshal, S. (1998). Social capital and value creation: the role of intra firm networks. The Academy of Management Journal, 41(4), 464-476.

[45] Kitapci, I. (2016). Cognitive social capital as an interdisciplinary concept. International Journal of Economic Studies, 2(3), $13-23$.

[46] Liao, J. and Welsch, H. (2005). Roles of social capital in venture creation: key dimensions and research implication. Journal of Small Business Management, 43(4), 345-362.

[47] Rindfleisch, A. and Heide, J. B. (1997). Transaction cost analysis: past, present and future applications. Journal of Marketing, 61(4), 30-54.

[48] Shin, H. D. (2003). The role of uncertainty in transaction cost and resource-based theories of the firm, $\mathrm{PhD}$ Dissertation, Graduate School of the Ohio State University, Ohio.

[49] Bromiley, P. and Cumming, L. L. (1995). Transaction costs in organizations with trust. Research on Negotiation in Organizations, 5(2), 219-247.

[50] Carey, S. and Lawson, B. (2011). Governance and social capital formation in buyer-supplier relationships. Journal of Manufacturing Technology Management, 22(2), 152170 .

[51] Ivens, B. S. and Blois, K. J. (2004). Relational exchange norms in marketing: a critical review of Macneil's contribution. Marketing Theory Articles, 4(3), 239-263.

[52] Dwyer, F. R. and Gassenheimer, J. B. (1992). Relational roles and triangle dramas: effects on power play and sentiments in industrial channels. Marketing Letters, 3(2), 187-200.

[53] Silkoset, R. (2013). Negative and positive effects of social capital on co-located firms' withholding efforts. European Journal of Marketing. 47(2), 174-197.

[54] Lu, H., Feng, S., Trienekens, J. H. and Omta, S. W. F. (2012). Network strength, transaction-specific investments, interpersonal trust, and relationship satisfaction in Chinese Agrifood SMEs. China Agricultural Economic Review, 4(3), 363378.

[55] Ganesan, S. (1994). Determinants of long-term orientation in buyer-seller relationships. Journal of Marketing, 58(2), 1-19. 
[56] Doucette, W. R. (1996). The influence of relational norms and trust on customer satisfaction in inter firm exchange relationship. Journal of Consumer Satisfaction, Dissatisfaction and Complaining Behavior, 9(5), 95-103.

[57] Miller, N. J., Besser, T. L. and Weber, S. S. (2010). Networking as marketing strategy: a case study of small community businesses. Qualitative Market Research: An International Journal, 13(3), 253-270.
[58] Bstieler, L. (2005). The moderating effect of environmental uncertainty on new product development and time efficiency, Journal of Product Innovative Management, 22(4), 267-284.

[59] Boyle, B., Dwyer, F. R., Robicheaux, R. A. and Simpson, J. T. (1992). Influence strategies in marketing channels: Measures and use in different relationship structures. Journal of Marketing Research, 29(4), 462-473. I73. 